\title{
Conducting Archaeogaming \& Protecting Digital Heritage: Does the Future for Archaeology Lie in The Immaterial
}

\section{La Conduction de l'Archaeogaming et la Protection du Patrimoine Numérique: I'Avenir de l'archéologie repose-t-il dans l'Immatériel?}

\author{
Benjamin Hanussek ${ }^{1}$ \\ ${ }^{1}$ Institute of Archaeology, University of Warsaw, Poland, benjamin.hanussek@gmail.com
}

Biographical Note: The author is a student of archaeology with a background in economic psychology. He is currently writing his thesis on the transition of board game design in Middle Kingdom Egypt. Besides that, his extracurricular research concerns the perception and theory of archaeology and heritage in the digital era, with a special interest in digital games and museums as transmitter of past realities.

\begin{abstract}
Digital games have become considerable and influential cultural transmitters throughout the past years. As social sciences had grasped the importance of this medium as an object of study, the field of archaeology has increasingly taken notice of the digital leisure worlds of millions of players. Studying games as artefacts or archaeological sites have been therefore pioneering research programmes by scholars like Andrew Reinhard in order to test the boundaries of the archaeological framework, as also to generate important insight on our society by applying archaeological methodology on digital games. The aim of this paper is to discuss the possible role of archaeology in its conjunction with video games and tries to establish a critical perspective towards the enthusiastic first wave of the archaeology of video games.

KEYWORDS. Digital Archaeology, Digital Heritage, Digital Games, Archaeological Theory, Archaeogaming.
\end{abstract}

\section{Introduction}

The digital revolution our world has been pursuing since the commercialisation of the internet (Twenge, 2018) has changed all aspects of our (western) life: the way we learn, interact socially, perceive the world and especially the way how we spend our leisure time.

While it is unquestionable that the concept of "play and game" is an universal one, embedded in every known culture (Huizinga, 2016) its role nowadays has reached of ungraspable influence on us through its fusion with computer sciences. Digital games ${ }^{1}$ have become therefore an omnipresent and omnipotent entity lingering on our smartphones, tablets, consoles and computers; ready to give us pleasure, fun and challenge on demand: the casual revolution (Muriel and Crawford, 2018: 3). The implication of digital games in our society is understated by the growing amount of literature on the topic (popular and scientific) (Chapman, 2016), the billion-dollar fold revenues of the game industry (Muriel and Crawford, 2018, p. 31) and other aspects like gamesque behaviour patterns, called gamification, which are transported from the virtual realm into the private and professional life in order to stimulate motivation and cognition (Ruffino, 2018: 28); possibly the contemporary equivalent to social engineering.

\footnotetext{
${ }^{1}$ It was decided, as suggested by Andrew Reinhard, to use the term digital game instead of the conventional term video game in order to shake off the undermining implications mass media has associated with the term video game.
} 
The importance of digital games for archaeology has been relentlessly forwarded by a growing pool of archaeologists with fruitful projects on studying digital games' ontology and epistemology with (theoretical) archaeological methods in order to retrieve valuable data on our contemporary society (Mol, 2014; Morgan, 2017; Reinhard, 2018). Also, ways in relaying archaeological knowledge through digital games are being studied (Ariese-Vandemeulebroucke, Boom, Mol, \& Politopoulos, 2017).

The unarguable need to deal with games in archaeology derives from the notion of digital games as digital heritage which "includes texts, databases, still and moving images, audio, graphics, software and web pages." (Macmillan, 2015: 96). Digital Heritage which logically derives from material heritage is, even without being aware of any theoretical frameworks, an essential concern for archaeology.

Still what it seems to lack is a critical perspective. A kind of research based on the model of Heinz von Foerster's ${ }^{2}$ second order. The second order according to Foerster adds another reflective dimension to a stream of thought and enables the researcher to question and enhance the quality of the field of research (von Foerster and Pörksen, 2001: 114-121).

It is evident that all research in the field of digital archaeology concerning digital games has been mostly focusing on the positive aspects in proving the applicability of archaeological methodology on the synthetic space (Hanussek in press), the value and importance of combining archaeology with the study of digital games. These novel approaches have led to a huge progress in archaeological theory but by now it seems that "theories are fabricated only in order to accommodate known facts." (Lakatos 1978: 5). The mathematician Imre Lakatos ${ }^{3}$ would label this development as an attitude of a degenerating research programme (Lakatos, 1978).

The goal of this paper is to calculate ${ }^{4}$ the generated progress in the field of digital game archaeologies $^{5}$ and confront it with understudied concerns in its own field in order to establish a critical counterweight. The idea of this paper is neither to strengthen the importance of digital games in archaeological studies nor to discredit the work and research of the growing number of archaeogamers (Reinhard, 2018) but to add an overdue critical dimension. Digital game archaeologies have reached a point of "maturity to allow diversity, controversy and uncertainty" (Hodder, 2003: xii). Therefore, the injection of a second order research and its repercussions will serve as the ultimate examination of the relevance of this field for a progressive future for digital archaeologies in general.

Therefore, the second section will open the discussion with a summary on the primal core concepts that drive the field of digital game archaeologies. In order to give a variation of the targets that can be pursued in this field, Reinhard's concept of Archaeogaming (Stream of York) and Mol's concept of the interactive past (Stream of Leiden) will serve to illustrate the status quo.

\footnotetext{
${ }^{2}$ Heinz von Foerster, born 1911, was a polymath (mainly centred around physics and philosophy) who became famous for his Biological Computer Laboratory at the University of Illinois and his works on cybernetics

${ }^{3}$ Imre Lakatos, born 1922, was theoretical mathematician who became a scholar at the London School of Economics where he worked with important contemporaries as Karl Popper. He became famous for his discourses on the fallibility of scientific research programmes
}

\footnotetext{
${ }^{4}$ The term calculate is used according to its semantic root which means „to set into relations “ and not as to calculate from a mathematical perspective
}

\footnotetext{
${ }^{5}$ The term digital (game) archaeologies is used to overarch every concept that combines archaeology with digital games and digital heritage. It is to be understood as a subfield of digital archaeology
} 
The third section will be introduced under the scope of von Foerster's concept of first- and second-order sciences and will be further elaborated by Lakatos' methodology of scientific research programmes in order to establish a critical and self-reflective overview on the field of digital game archaeologies.

The fourth section will use the case of Ubisoft's Notre Dame ${ }^{6}$ to present a rather questionable issue surrounding the field of digital game archaeologies which still neglect complex problems as for example the copyrighting of material culture and the total commercialisation of heritage.

Lastly the fifth section will relate the preceding sections and conclude the discussion under the notion of materiality and will try to answer the question if archaeology should position itself as a mediator of material culture or if this role has become obsolete in perspective on the digital avalanche that our society has faced (and is still facing).

This paper can be seen as the sum of two parts. The former (section 2 and 3) which serves as a preface in form of a historical archaeological account and the latter (section 4 and 5) as actual case and critical account.

\section{On the State of Digital Game Archaeologies}

In order to illustrate the core concepts and mission of digital game archaeologies this section will present two streams in this field which have two fairly different emphasises concerning the conjunction of digital games and archaeology. The idea to distinguish and refer explicitly to specific actors in this field serves a post-structuralist nature; as transparency seems fit to improve the understanding of actors behind the emergence of specific (archaeological) thought (Foucault, 2002). The current main actors or streams ${ }^{7}$ of thought that can be divided are the Stream of Leiden which focuses on the dissemination of archaeological thought through digital games and the Stream of York which focuses more on the archaeologically measurable ontology of digital games.

\section{(a) Stream of York: Archaeogaming}

The Stream of York does pursue a rather abstract approach in hindsight to traditional archaeology. This particular stream of archaeological thought which surrounds itself by Sara Perry ${ }^{8}$, Coleen Morgan and Andrew Reinhard pursues a contemporary archaeology (Holtorf, 2007) under the notion of the near-immediate (Reinhard, 2018: 5).

The digital game is thus part of our material culture in the near-immediate ${ }^{9}$. The approach builds itself upon the idea that "videogames provide landscapes and objects that are productive for

\footnotetext{
${ }^{6}$ On the 15th of April, 2019 the Notre-Dame de Paris has caught fire and was majorly damaged. The game developer Ubisoft that produces the game series Assassin's Creed has then offered one of the games of the series for free (the offer lasted one week), which contained a full-scale digital reconstruction of the gothic cathedral.

${ }^{7}$ The term stream is used in a similar manner as schools in philosophical discourses. Anyhow to name these approaches schools seems to static in this context, therefore stream serves to conceptualise the idea of approaches with a kind of fixed source that on the other hand also act dislocated

${ }^{8}$ Even though Perry is to be located in the general field of digital humanities rather than digital (game) archaeology she has been fundamental for the philosophy behind approaches of Reinhard and Morgan

${ }^{9}$ The concept of the near-immediate bases on the notion that the perception of time prior to the industrial revolution has been completely different to the way we perceive time now. The idea sees the density and sequence of technologies as a more reasonable benchmark to define temporalities in our contemporary society.
} 
archaeological investigations" (Morgan, 2016: 9). While Morgan has been testing the boundaries of archaeological theory concerning the general digital space; USB sticks as archaeological sites (Perry and Morgan, 2015), Reinhard has been able to craft something close to a framework to this specific approach. His concept of archaeogaming (Reinhard, 2018) embodies many approaches. Important for this piece of work is the notion that archaeogaming interprets "games as sites, built environments, landscapes and artefacts, no different than any place on earth that has been manipulated, managed and transformed by people past and present." (Reinhard, 2018, 2). The idea is to transport terrestrial archaeological methodology into a synthetic space (Hanussek in press) and as an effect to complement interpretational narratives of the fields of game studies and sociology, which lack the notion of materiality. Archaeogaming enables therefore the researcher to study digital games as an artefact in order to study our society. Even though it is debatable if archaeogaming offers An Archaeology (Orser, 2015: 6) or simply the proof of the importance of archaeological theory in studying the immaterial (Buchli, 2016), it is unquestionable that Reinhard was able to manifest an idea of a modern archaeology and influence the international archaeological discourse according to contemporary socio-cultural developments (Trigger, 2006: 38).

\section{(b) Stream of Leiden: The Interactive Past}

The Interactive Past can be considered as an outlet of a circle of scholars that follow a rather extrinsic and didactic pursuit in the quest of combining archaeology with digital games (ArieseVandemeulebroucke, Boom, Mol, \& Politopoulos, 2017). That the potential of video games can serve as a narrative for the past (Chapman 2016, 136-138) and also as a "mediated experience" (Muriel and Crawford, 2018: 86) of the past is the crucial agenda of the Stream of Leiden. The core concept of this stream of thought has gathered under the banner of the VALUE Foundation ${ }^{10}$; A group of scholars from the Leiden University that tries to explore the avenues that can help to transmit archaeological knowledge through games in a more sustainable manner to students of archaeology and also a wider field of the people. Even though the Stream of Leiden can be considered of much more pragmatic in nature (providing workshops ${ }^{11}$, conferences and lectures) it does not fail to recognize the intrinsic value of digital games as a container of heritage. "The games discussed here create immersive virtual environments, inspired by and incorporating traditional values, teachings, and knowledge (...) demonstrating an immense capacity for the expression and protection of tradigital knowledge." (Hughes, 2017: 34). The contribution for the progression of digital game archaeologies through the work of the members of the VALUE Foundation cannot be marginalised as it has proven the practical and valid connection between archaeology and digital games in an extensive manner with considerable outreach into the traditional academia of archaeology as also into the general public. The Stream of Leiden clearly pursues its goal of transporting the past into the present through involvement. "Participation and demonstration are such priceless ingredients of interpretation that we should diligently search for possibilities and never let slip a real opportunity for including them." (Tilden, 1977: 76).

To sum up one could say that while the Stream of York is mainly concerned with the ontology of digital games from an archaeological perspective the Stream of Leiden is trying to study and apply the epistemology of games as an interactive medium in transmitting archaeological knowledge (see fig. 1). These accentuations surely portrait only the hard core ${ }^{12}$ (Lakatos, 1978: 4-5) of the particular

\footnotetext{
${ }^{10}$ The VALUE Foundation was founded in 2017 and consists of A. Mol, V. Vandemeulebroucke, C. Ariese-Vandemeulebroucke, K. Boom and A. Politopoulos

${ }^{11}$ A workshop hosted by A. Mol and A. Politopoulos at the CAA Conference 2019 in Krakow enabled the participants to craft with the open source software twine an interactive storytelling game in which archaeological subjects could be playfully conveyed

${ }^{12}$ After Lakatos a hard core is a fundamental theory of a research programme. The hard core cannot be contradicted
} 
stream of thought but they help to realise that the field of digital game archaeologies has already been able to establish itself to such an extent that it has distributed itself already into further subfields. Anyhow, it is also important to mention that both streams do not contradict each other in their philosophy and are driven from the same positive enthusiasm that endorses the empirical exploration of digital games as an object of study and dissemination tool of archaeological importance. The efforts of those two streams have since then being several times repeated and even though the possible empirical experiments are due to the nature of digital games infinite, the theoretical basis has not provided any novel prospects on much else except that the study of digital games from an archaeological perspective is important for its own sake.

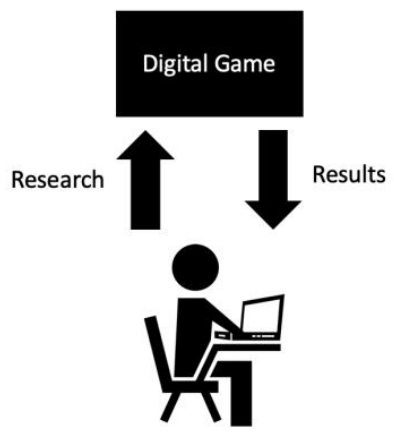

Digital Game Archaeologist (York)

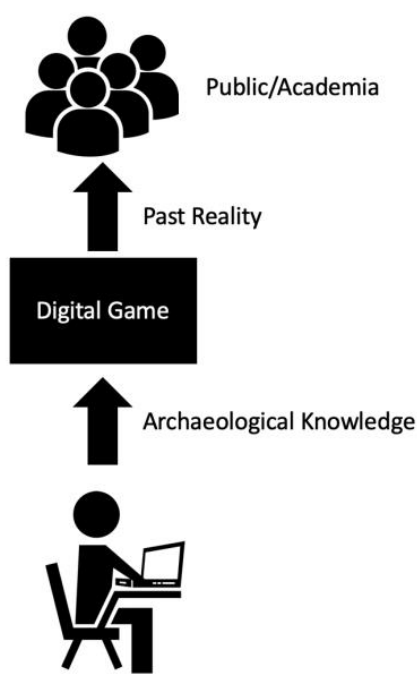

Digital Game Archaeologist (Leiden)

Figure 1. Simplified model of the main approaches in digital game archaeologies. Illustration by the author

According to Heinz von Foerster's concept of first and second order sciences (von Foerster and Pörksen, 2001: 114-121; von Foerster, 2003: 243-244) it seems reasonable to appoint the previous presented stream of thoughts as part of a first order (or first wave) of an established scientific field. "The first-order domain/level of research can be characterized as an exploratory problem-solving operation $^{13}$. It is designed, on the one hand, for the exploration of the natural and social worlds as well as for the construction of a technological sphere and, on the other hand, for the axiomatization and orderings of the possible worlds of logic (...)" (Mueller and Riegler, 2014: 8).

A first order that manages to establish itself in a field of science does according to von Foerster tragically conceive a blind spot (von Foerster, 2003: 284) which makes it sterile towards the generation of novel facts and critical self-reflection. Looking at the growing field of digital game archaeologies it seems undoubtable that the latest research in this field has brought little novel insight and unquestionably uncritical research towards questions of copyright and an apparently decreasing consciousness for materiality (Stobiecka, 2018). This state of a research field can be attributed with a deficiency of a second order "and the only way to overcome such deficiencies is with therapies of the second order." (von Foerster 2003: 284).

\footnotetext{
${ }^{13}$ The problem-solving operations these streams were pursuing were the (by now successful) justification attempts tob e accepted as legitimate part of the archaeological science through practical experiments and projects in public archaeological domains (Leiden Stream) and theoretical and contemporary archaeological domains (York Stream)
} 


\section{Validating the Need for a Second Order in Digital Game Archaeologies}

This section will apply Imre Lakatos' Methodology of Scientific Research Programmes (Lakatos, 1978) on the state of research in digital game archaeologies in order to observe if the research that is still being undertaken in the field has degenerated or is still being progressive ${ }^{14}$ (Lakatos, 1978: 56). At this point it is sufficient to identify progressive research as having theoretical content that exceeds the empirical and degenerating research that has empirical content that exceeds the theoretical (Wild, 1986: 24).

This identifiable life cycle of research agendas (Mueller and Riegler, 2014) can be analogised by comparing the emergence of digital game archaeologies (but also digital archaeology in general) with the emergence of processual archaeology.

"[I]n the early 1960s, a group of American processual archaeologists launched an all-out attack on culture-historical archaeology, which they proposed to replace with an approach that was evolutionist, behaviourist, ecological, and positivist in orientation." (Trigger, 2006: 368). This progress of archaeological science was as in the case of the first order digital game archaeologies centred around the sensation of computer sciences in awe of their possibilities and chances (Trigger, 2006: 540). Stobiecka has been able to establish the concept of digital escapism (Stobiecka, 2018) in the context of archaeological museums that is able to grasp many aspects surrounding the rejoicing between archaeology and computer sciences.

Anyhow, to calculate the emergence of digital game archaeologies in perspective towards the rise of the new archaeology (Binford, 1972) of the 1960s it must be added that the preceding concept of punk archaeology ${ }^{15}$ (Caraher, Kourelis, \& Reinhard, 2014) was the needed establishment for digital game archaeologies to unfold itself fully. According to Hodder this aspect mirrors "the gradual development of an idea, or rather an inter-related set of ideas" (Hodder, 2016: 85 ) that enabled the vision of a valid connection between digital games and archaeological science to prosper.

As in the processual era, punk archaeology and the succeeding digital game archaeologies both benefitted from "the introduction of philosophers to archaeo-thinking", which "meant that archaeologists began to explore topics entirely new to them" (Orser, 2015: 21). After Lakatos this circumstance in processual archaeology as also digital game archaeologies can be measured as "progressive, by the degree to which [a] series of theories le[d] us to the discovery of novel facts." (Lakatos, 1978: 34). These novel facts can be generalised as the validation of possible extensions of the archaeological frameworks that enabled us to collect more data, analyse data differently and apply new methods. Looking at digital game archaeologies a decade ago one would have considered the methods that the current streams of thought pursue as unscientific while now this paper discusses this movement as an established branch. The same path can be identified for processual archaeology that has introduced prior refuted concepts like "systems view" (Renfrew and Bahn, 2004 (Binford, 1972): 163) which changed the way how archaeology was conducted for more than a decade.

\footnotetext{
${ }^{14}$ The concept of von Foerster does broadly identify the same patterns as Lakatos. The reason why Lakatos concept was chosen to elaborate the issue further is that Lakatos offers a more universally applicable definition of parameters to identify progressive (first order) and degenerating (second order) research

${ }^{15}$ Punk archaeology was the idea to transport archaeological methods to contemporary issues like the study of recent subcultures that have centred around punk (rock) music.
} 
It may be debatable if the new archaeology (Binford, 1972) ultimately failed to become more than a negative heuristic ${ }^{16}$ (Lakatos, 1978: 47) because its systemic approach tried to establish a universal "yardstick for measuring the past" (Hodder, 2003: 38) which corrupted its whole theoretical framework by hubris or if it turned degenerating due to the fact that its own limitations and inability to prospect novel theories forced a second order, namely post-processual archaeology, to replace it.

However, by now the processual analogy has served its goal to illustrate the state of affairs in which digital game archaeologies are to be located. Therefore, it is needed to introduce Lakatos formula on the evaluation of scientific research programmes to validate the claim for a second order of digital game archaeologies.

"A scientific theory $T^{17}$ is falsified ${ }^{18}$ if and only if another theory $T$, ${ }^{19}$ has been proposed with the following characteristics: (1) $T$ ' has excess empirical content ${ }^{20}$ over $T$ : that is, it predicts novel facts, that is facts improbable in the light of, or even forbidden, by T; (2) T' explains the previous success of $T$, that is, all the unrefuted content of $T$ is included (within the limits of observational error) in the content of $T^{\prime}$; and (3) some of the excess content of $T^{\prime}$ 'is corroborated." (Lakatos, 1978: 32)

So, if we turn our attention to condition (1) of Lakatos' formula we can claim to have established that the current state of digital game archaeologies fails to produce any new theoretical output in order to progress itself and that a second order is able to provide the general research in this field with new perspectives; copyright issues and the disappearing appeal of materiality have been briefly addressed in the first section and will be elaborated in the next section. It can also be argued that in light of condition (2) a self-reflective second order is capable of rationalising the success of the initial first order and can apply the results that have been extracted and cultivated until now. Concerning condition (3) one can say that the second order does provide already content that can be corroborated as it cannot be refuted that copyright issues concerning heritage do arise (Porsdam, 2015: 8-10) and that the understanding of materiality nowadays (in relation to our digitised society) has become a matter of archaeological concern (Gonzáles-Ruibal, 2013: 17-19). Ergo, there is a valid need to establish a new stream of thought, a new critical dimension and a new self-reflective approach towards digital game archaeologies to be able to detect its own flaws and to be able to become once more relevant and fruitful to the archaeological science in general.

\section{Ubisoft's Notre-Dame: Introducing Second Order Issues}

This section is dedicated to far reaching issues in the realm of digital game archaeologies that stay generally undetected and understudied due to the first order characteristics of digital archaeologies. In the following the case of Ubisoft's Notre-Dame ${ }^{21}$ is used to discuss subjects concerning copyright and digital policies, the transformation of material heritage into digital

\footnotetext{
${ }^{16}$ A negative example on how not to do science

${ }^{17} \mathrm{~T}$ = digital game archaeologies of the first order

${ }^{18}$ falsified = needed to be revised, as in this case the first order is cannot be falsified

${ }^{19} \mathrm{~T}^{\prime}=$ proposed (critical) digital game archaeologies of the second order

${ }^{20}$ The excess of empircal content of $T^{\prime}$ must found on novel theories

${ }^{21}$ Ubisoft's Notre-Dame is a full-scale digital reconstruction of the Notre-Dame de Paris by the Franco/Canadian game developer/publisher Ubisoft which was designed for the game Assassin's Creed: Unity. The concept of Ubisoft's Notre-Dame for this paper concerns always the burning of the actual Notre-Dame in April 2019
} 
heritage and questions on the notion of materiality in our contemporary society. The goal of this section is to visualise the aspects and importance of a critical digital archaeology to address issues that may affect the archaeological discipline as a whole.

On the $15^{\text {th }}$ of April the Notre-Dame de Paris, one of the most known gothic cathedrals, caught fire and was majorly damaged. Hence, the cathedral has been closed to the public until the reconstruction and restauration work is finished. The contributions and solidarities from public agents to the reconstruction of the cathedral have been tremendous. The French/Canadian publisher and developer Ubisoft may have contributed to the case in the most creative way. The publishing house provided its game Assassin's Creed: Unity for free. The game consisted of a full-scale digital reconstruction of the Notre-Dame cathedral (see fig. 2) (Hanussek, 2019).
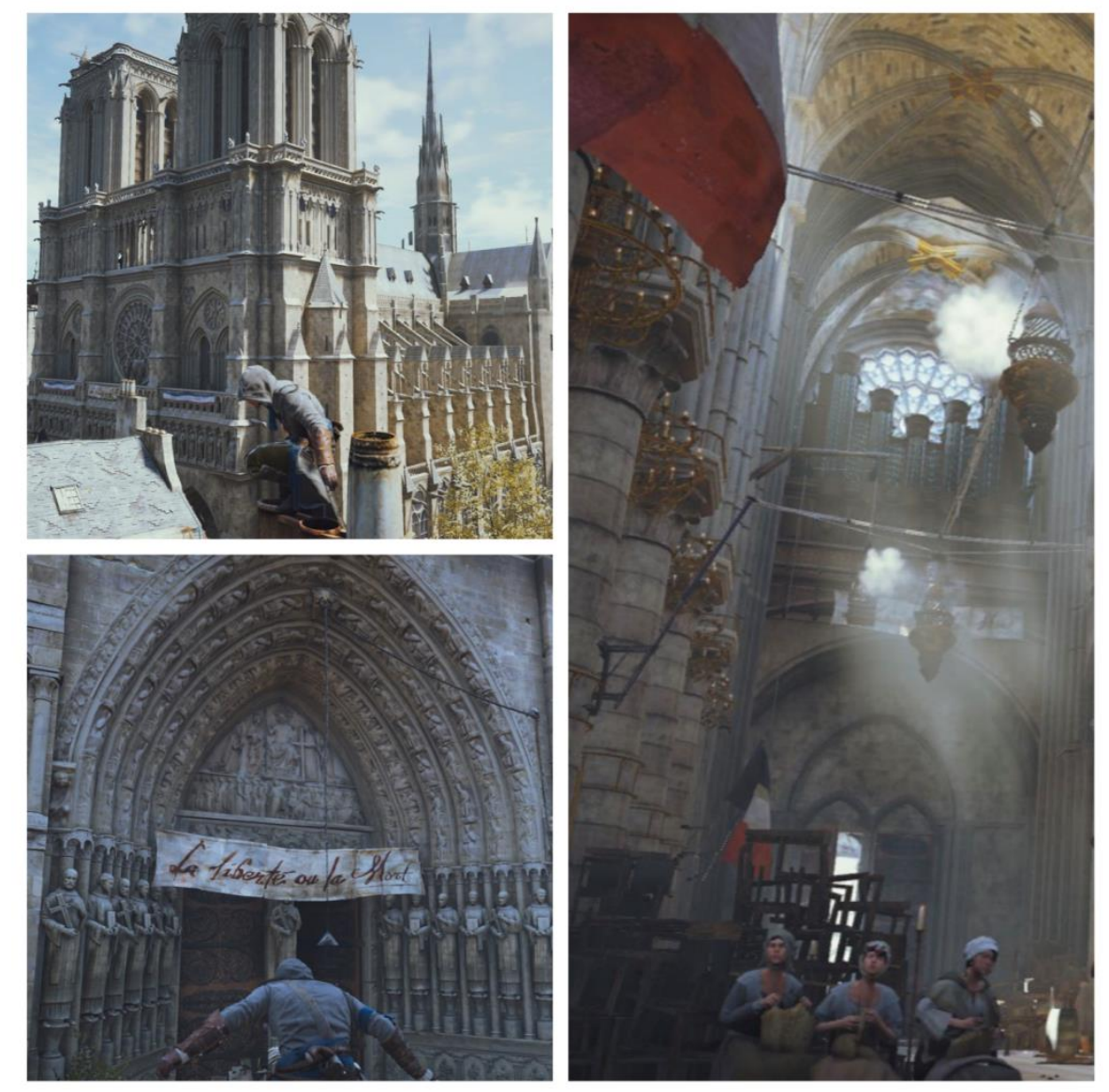

Figure 2. The Notre-Dame in Assassin's Creed: Unity. Courtesy of Aleksandra Stachyra

The present case at hand is unique and needs careful and rigorous investigation as its implication for archaeology must be considered. In order to sum up the aspects which constitute the issue, following actions must be highlighted: (a) material heritage is destroyed, (b) material heritage is substituted by digital heritage, (c) the substituted digital heritage is owned by a private company, (d) digital game archaeologies were not able to address the issue.

\section{(a) Material Heritage is Destroyed}

The basis from which the whole presented case derives off is the fact that material heritage has been destroyed. The Notre-Dame de Paris was declared world heritage in 1991 by the UNESCO (ICOMOS, 1991) and apparently bells, paintings, textiles and architectural features have been either damaged or fully destroyed (BBC, 2019). The destruction and entropic behaviour of material heritage is something natural (Shanks, 1998, pp. 16-17), seen either by the intentional destruction of material heritage like in the case of the Bamian Buddhas (Renfrew and Bahn, 2016, p. 17) and the Temple of Bel in Palmyra (Kamash, 2017) or the accidental destruction through negligence of 
precautions like it seems to be the case of Notre-Dame itself. Not to mention the variety of possibilities for material heritage to subject itself to destruction in nature; natural catastrophes, erosion, corrosion, (Price, 1995), et cetera.

\section{(b) Material Heritage is Substituted by Digital Heritage}

According to the cathedral's rector the monument will be closed down for around "five to six years"22 (CBC, 2019). So even though heritage is being restored to be once again publically accessible it is incapacitated for an immense period of time. It has been therefore Ubisoft's idea to fill this gap with their virtual version of the cathedral which is part of its game Assassin's Creed Unity. The game was offered for free and a donation of about 500.000 euro was granted for the restoration of the cathedral (The Guardian, 2019). The digital reconstruction has been carefully designed in a course of about two years with the help of a historian and is to be perceived as an "artistic creation, not a scientific one." (Forbes, 2019). Still the reconstruction can be considered as the most ambitious and interactive reconstruction to date of the monument. The digital reconstruction is available since 2014 but went now significantly viral through the incident. This also led Ubisoft to increase its server capacities (PC Gamer, 2019) in order to withstand the onslaught of virtual migrants (Reinhard 2018: 104-105) keen on dwelling around the digital cathedral.

It is also clear that this act has helped to raise international awareness on the loss of heritage to millions of gamers that might have never came in touch with the monument. It is interesting to speculate on how the perception of monumental heritage as the Notre Dame is altered through its transformation into digital heritage. The perception of time in our contemporary society seems to constitute our conceptualisation of past realities (Holtorf, 2017; Meskell, 2013: 245) and a case like this offers a perfect possibility to study the shift in meaning of heritage to the public through a digital game which mirrors western society with its multi-temporality (Morton, 2013: 119-121).

\section{(c) Substituted Digital Heritage is owned by a Private Company}

While the real Notre-Dame stays inaccessible, Ubisoft owns a publically accepted and celebrated substitute. Second thoughts seem legitimate in light of the fact that a monument which underwent destruction is currently only accessible through a propagated digital reconstruction which is owned by a corporate body of the entertainment industry (Hanussek, 2019). One needs to understand the implication this holds for the mediation of cultural heritage. Even though it is unquestionable that Ubisoft has acted out of great virtue and solidarity it seems that the archaeological narration of this monument has been completely compromised by a corporate body (Harrison, 2000).

It makes sense to increase the scope and discuss in this subsection if there is any legal basis surrounding this topic. So, can heritage be copyrighted? At first glance, no. "Copyright is a private property right whereas cultural heritage rights are enjoyed in community." (Porsdam 2015: 8). Heritage can therefore not be owned by a private body. But considering the fact that digital heritage is accepted and protected by the UNESCO (Macmillan 2015: 96) as a form of cultural heritage does this mean that Ubisoft's Notre-Dame holds a triple status in being software, thus private property (Reynolds, 2016: 123) on one side, while being digital heritage by its own and a copy of material heritage on the other side? If this means that a grey zone offers the legal basis for cultural heritage to be owned by a private body and used for commercial purposes, steps must be undertaken to "limit the privatisation of cultural heritage through copyright" (Porsdam 2015: 8). Even though this case can also be seen as the private sector's contribution "to create new ways of funding digitisation of cultural material" (European Commission, 2011: 4) it stays debatable if heritage must stay

\footnotetext{
${ }^{22}$ Recent news surrounding the count of over 2 billion euros seem to decrease the anticipated restoration period
} 
exploitable to such an extent, being "a public asset at the service of other cultural enterprises" (Colomer, 2019: p. 125). In addition, it seems difficult to illuminate the issue with the perspective from within the game industry as "actors are often obfuscated by nondisclosure agreements" (Conway and de Winter, 2016: 2).

\section{(d) Digital Game Archaeologies were not able to Address the Issue}

There has been no visible vocalisation of any projects to confront the loss with active initiatives nor was there any critique to the fact that material heritage could be substituted by a private company or that the transformation of material heritage into digital heritage could offer something else than benefits. Contemporary digital game archaeologies have not been able to detect such an issue prior to the event nor afterwards.

The issue that has been presented here may not be as visible as the opportunities that the game Minecraft holds for recreating the past (McGraw, Reid and Sanders, 2017: 167-170) but the implications are fundamental for a science that is based on the importance of material culture (Orser, 2013: 146). On one hand, the academic narration and the educational merit of material heritage has been replaced to the public by the sensationalism surrounding a digital copy owned by a private company while on the other hand the digital has been presented to the public as ultima ratio; the digital as successor of materiality. "The ideological underpinnings of the technologies that surround us in our daily lives are frequently invisible" (Vie, 2016: 57) and must be critically questioned if archaeology decides to delegate the interpretation and dissemination of their results to the gaming industry (see fig.3).

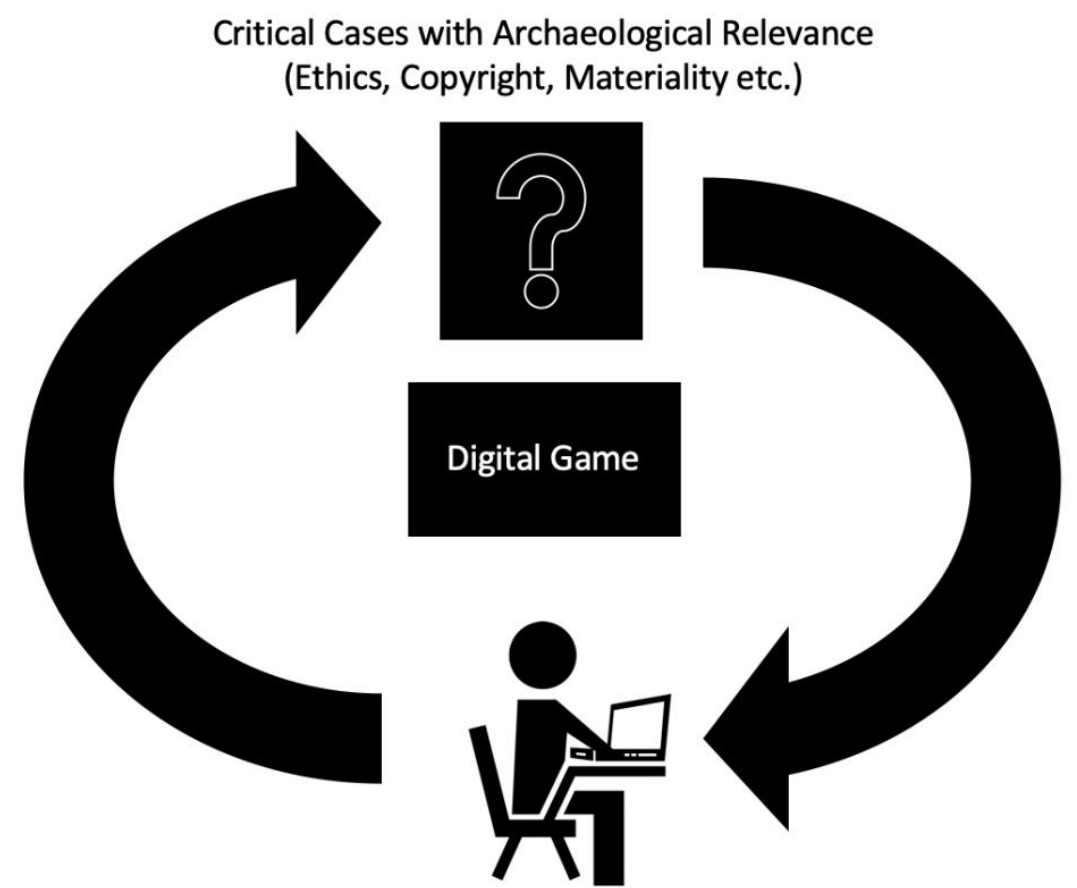

Digital Game Archaeologist (Second Order)

Figure 3. Simplified model of the main approach in a critical digital game archaeology. Illustration by the author.

\section{Does the Future for Archaeology Lie in The Immaterial?}

It has been so for recapitulated in how far digital game archaeologies operate and how they changed archaeological thought but also how they fail to detect important research questions. This paper has on various occasions pointed towards the notion of materiality and will stress in this 
section further on it. The idea of this section is to give a perspective on why digital game archaeologies may not succeed in being beneficial to archaeology if archaeological studies of digital games serve the popularity of games more than that of a sustainable archaeology itself. It is in a complex case as this, that shows that archaeology must find its role again as a mediator of material culture in order to create sustainable material realities (Haefner 1985: 218). Archaeology should not subdue itself so naively to the ongoing digitisation and drift into an objectless world (Buchli, 2016: 144). It may be said that archaeological thought has the responsibility to create the importance of tangible heritage. While the rise of Object-Oriented Ontology was a quantum leap in trying to give materialities (Domańska, 2006) a respectable stance, digital archaeologies seem to reverse the progress. On one side stating the immense benefits of digital technologies for archaeology on the other side ignoring the technology's own agency and influence on our interpretations. The sensory experience of archaeological interpretation has become "distilled into unisensory studies" (Favro, 2013: 251).

Digital heritage may seem charming and exciting to study but after all its ontology may has more to do with the blurred dancing shadow in Plato's cave (Gergely, 1986: 255) than something deserving the admiration that the synthetic space does receive from academia (Ruffino, 2018: 8-11). It should be the archaeologists quest to step out of the cave and find the source of the immaterial fantastic projection. These could reveal themselves as more material than one might want to handle; server farms, plastics, electronics, aluminium and garbage. Are these the materialities of digital games? Is this the illusionary, uncanny and dislocated 163 billion dollar hyperobject (Morton, 2013) we consider as the ultima ratio? (Ruffino, 2018)

So, is this the future for archaeology? Does the Future for Archaeology lie in the immaterial?

In order to attempt to answer this question the dichotomy between the material and immaterial must be diluted (Olsen, Shanks, Webmoor and Witmore, 2012: 8). Only then we see that the answer does not matter. Rather how we try to answer the question is of importance. Cornelius Holtorf once stated that one of the most important tasks of archaeology is bound to the action of conducting archaeology and not to its results (Holtorf, 2007). Doing archaeology to reconnect humanity with the past and reconnecting it with the material that was left by our ancestors.

"An enduring sense of heritage from our fathers is vital to our future, and this knowledge is to be gained by keeping the past a living reality." (Tilden, 1977: 77). Digital Game Archaeologies can help to wield the digital game for archaeology. The potential of digital games as a new form of public archaeology (Hanussek, in press) and as an object of study (Reinhard, 2018) has been proven throughout the years. Anyhow digital games are not anymore, the output of a group of nerds producing a medium that is free of all boundaries (Barton, 2008). Digital games are now the output of a hard core economic deus ex machina which generates more revenues than those of the film and music industry combines (Plothe, 2016: 51). The products of this industry possess an ontology that is beyond the scope of uncritical research. It may be said that game scholars (or archaeogamers) are "called upon to illuminate power relations and networks of production to interrogate ideological systems that may or may not be in the best interest of the people involved." (Conway and de Winter, 2016: 3).

The studies on digital games through the framework of archaeology are a reasonable contribution to the study of the Anthropocene (Reinhard, 2018: 59) and challenges our own theoretical framework. The study of digital games has revealed that the past can be represented as something beyond facts where the question about a true or real interpretation becomes somehow obsolete in light of the fiction which enables players to interact with a past reality like never before (Morgan, 2019). The archaeological framework is thus forced to become flexible and fluid in order to abolish the static dogma of standardisation (Latour, 2005: 143-149). 
Nevertheless, critical research must not become "unaware of the presence of the medium" (Vie, 2016: p. 57, after Warnick, 2002) in contrast to its transparency that forces us to ignore the dislocated action that is forced upon us. One might be fooled by the reality of digital technologies that blinds us to our own "Western bias, which sees affect as synonymous with visual fidelity. (...) Again, a lack of diversity is evident in this kind of articulation, where the predominantly white, Western worldview is entrenched discursively as common sense." (Conway and Crawford, 2016, p. $92)^{23}$.

Even considering the approach of the Stream of Leiden to digital game archaeologies needs to reflect on its approach of gamifying archaeology. Gamification has been questioned in the latest outputs of academic game studies as neoliberal form of exploitation (Muriel and Crawford, 2018; Ruffino, 2018) where "fun is the new work.". The growing exploitation of playfulness though business since the industrial revolution has been ironically observed by the father of ludology, Johann Huizinga from the Leiden University (Huizinga, 1938, p. 200-211). "The illusion of interactivity sponsors a sense of agency - but agency has been externally predetermined or predesigned." (Muriel and Crawford, 2018: 67) which might compromise the experience of a past reality after all to the narrative of a prefixed limited algorithm (Reinhard, 2018, p. 129). The video game can be therefore seen as a dispotif. A limitation to themselves and a manifestation of the conditions of its socio-cultural background (Muriel and Crawford, 2018: 65) and inevitably of its maker's hand.

So, what does this tell us about Ubisoft's Notre-Dame?

\section{Conclusion}

It must be evident to the reader that the topic has the potential to be elaborated beyond the word limitation of this paper. Nevertheless, the paper has served its purpose as an introduction to a second order of digital game archaeologies; a critical study on itself. This paper bases on the vision of an archaeology with a responsibility in this digitised 21 st century. A vision of forming a bridge between the human and the thing. Archaeology must form a cognitive technology (Buchli, 2016: 51) enabling us to augment a material reality with thought encouraging values and an inspirational merit. Digital technologies can help us to develop a modern archaeology if we take the time to evaluate the processes our world undergoes and if we take the time to evaluate the technologies that change our world.

One of those world-changing technologies are digital games. "Digital games as cultural artifacts are some of the most technically complex, intellectually provocative, ethical challenging, and politically contentious products in contemporary society" (Conway and de Winter, 2016: 1-2) and they (as different kind of media before) have changed archaeology (Clack and Brittain, 2007). The way we gather data, evaluate results and perceive ourselves as archaeologists. Still in order generate solid interpretations that hold scientific integrity we cannot allow ourselves to be too immersed into the object of study. We need to maintain a professional relationship to the game (Muriel and Crawford, 2018: 159). The impression arises that research which includes the act of gaming as epistemological approach is obscured by the excitement of the act in itself. This may be something that will define the great border between the interpretational mechanisms of traditional archaeologies and digital archaeologies; cognitive technologies versus digital technologies.

\footnotetext{
${ }^{23}$ Conway and Crawford were discussing the implication of game classification and review boards in Australia which were consisting of mainly middle aged white men. These boards are deciding about visual censorship in digital games. This was contrasted to the Australian aboriginal culture which sees sound as more important than visual representation.
} 
We have gained a lot from digital games but are we also about to lose something? Should we try to archaeofy gaming instead of letting archaeology be gamified? Does more time spent online and being immersed in gaming correlate with an ignorance towards the real world and its material culture? Does the digital revolution devour its own children?

Anyhow, how many contradictions there might be to discover from this critical approach one thing should be said at last: A digital archaeology must serve a material archaeology

This may be termed the hard core of an alternative stream in digital archaeologies. A second order, hopefully to be revised and replaced by a third order once this approach has served its purpose.

\section{Acknowledgements}

I would like to thank Andrew Reinhard and Sara Perry for their correspondence, Angus Mol and Aris Politopoulos for their workshop and discussion on an interactive past and Monika Stobiecka for her remarks on my work and interesting discussions on the importance of a critical archaeology. Also, I would like to credit Aleksandra Stachyra for her provided in-game footage of the game Assassin's Creed: Unity and Lea Assad for the French translation of the title.

\section{References}

Ariese-Vandemeulebroucke, C. E., Boom, K. H., Mol, A. A., \& Politopoulos, A. 2017. The Interactive Past: Archaeology, Heritage \& Video Games. Leiden: Sidestone Press.

Barton, M. 2008. Dungeons and Destops: The History of Computer Role-Playing Games. Wellesley: A K Peters.

BBC. 2019. Notre-Dame fire: Treasures that make it so special. [online] [accessed June 2019]. Available at: $<$ https://www.bbc.com/news/world-europe-47937775>

Binford, L. 1972. An Archaeological Perspective. New York: Seminar Press.

Buchli, V. 2016. An Archaeology of the Immaterial. Oxon: Routledge.

Caraher, W., Kourelis, K. \& Reinhard, A. eds. 2014. Punk Archaeology. The Digital Press.

CBC. 2019. Notre-Dame to be closed as long as 6 years, Paris cathedral's rector says. [online] [accessed July 2019]. Available at: <https://www.cbc.ca/news/world/notre-dame-fire-investigation-1.5101302〉

Chapman, A. 2016. Digital Games as History: How Videogames Represent the Past and Offer Access to Historical Practice. Oxon: Routledge.

Clack, T., \& Brittain, T. 2007. Archaeology and the Media. Walnut Creek: Left Coast Press.

Colomer, L. 2019. Stones, Books and Flags: Born and the Role of Archaeological Heritage Management under the Barcelona Model. European Journal of Archaeology, 22(1), 111-130.

Domańska, E. 2006. The return to things. Archaeologia Polona, 44, 177-185.

European Commission. 2011. On the Digitisation and Online Acessibility of Cultural Material and Digital Preservation. Brussels: European Commission.

Favro, D. 2013. To be or not to be in Past Spaces: Thoughts on Roman Immersive Reconstructions. In S. Bonde, \& S. Houston, eds. Re-Presenting the Past: Archaeology Through Text and Image, pp. 246-273. Oxford: Oxbow Books.

Forbes. 2019. Ubisoft Is Giving 'Assassin's Creed: Unity' Away For Free To Honor Notre Dame. [online] [acessed 29 June 2019]. Available at: <https://www.forbes.com/sites/davidthier/2019/04/17/ubisoft-is-giving-assassins-creedunity-away-for-free-to-honor-notre-dame/\#cee852f2ec27>

Foucault, M. 2002. Archaeology of Knowledge (2nd ed.). Oxon: Routledge.

Gergely, S. 1986. Wie der Computer den Menschen und das Leben Verдndert. Mьnchen: Piper. 
Haefner, K. 1985. Wege in die Informationsgesellschaft: Psychologische und Gesellschaftliche Perspektiven der Computerisierung. In ICOM, \& H. Auer, eds. Chancen und Grenzen moderner Technologien im Museum, pp. 207223. Msnchen: Sauer Verlag.

Hanussek, B. 2019. Digital Heritage through Video Games: A critical view on Ubisoft's Notre Dame. [online] [accessed June 2019]. Available at: <https://www.heritagedaily.com/2019/06/digital-heritage-through-videogames-a-critical-view-on-ubisofts-notre-dame/123883>

Hanussek, B. in press. Archaeogaming: Applying terrestrial methodology on the synthetic play space. 20th MISSA: 500 Thousand Most Difficult Years. Poznan: Poznan University Press.

Harrison, J. 2000. Outsourcing in Museums. International Journal of Arts Management, 2(2), 14-25.

Hodder, I. 2016. Entangled: An Archaeology of the Relationship between Humans and Things. Chichester: WilleyBlackwell.

Hodder, I., \& Hutson, S. 2003. Reading the Past: Current Approaches to Interpretation in Archaeology (3rd ed.). New York: Cambridge University Press.

Holtorf, C. 2007. Archaeology Is a Brand! Oxford: Archaeopress.

Holtorf, C. 2017. The Archaeology of Time Travel: Experiencing the Past in the 21st Century. Oxford: Archaeopress.

Hughes, G. 2017. Tradigital Knowledge? Indigenous video games, copyright, and the protection of traditional knowledge. In A. A. Mol, C. E. Ariese-Vandemeulebroucke, K. H. Boom, \& A. Politopoulos, eds. The Interactive Past: Archaeology, Heritage \& Video Games, pp. 33-52. Leiden: Sidestone Press.

Huizinga, J. 2016. Homo Ludens: A Study of the Play-Element in Culture. Kettering: Angelico Press.

Lakatos, I. 1978. The Methodologyy of Scientific Research Programmes: Philosophical Papers (Vol. 1). (J. Worall, \& G. Currie, Eds.) Cambridge: Cambridge University Press.

Latour, B. 2005. Reassembling the Social: An Introduction to Actor-Network-Theory. Oxford : Oxford University Press.

Macmillan, F. 2015. Arts Festivals as Cultural Heritage in a Copyright Saturated World. In H. Porsdam. Copyrighting Creativity: Creative Values, Cultural Heritage Institutions and Systems of Intellectual Property, pp. 95-112. Surrey: Ashgate.

McGraw, J., Reid, S., \& Sanders, J. 2017. Crafting the Past: Unlocking new audiences. In A. A. Mol, C. E. ArieseVandemeulebrocke, K. H. Boom, \& A. Politopoulos, eds., The Interactive Past: Archaeology, Heritage \& Video Games, pp. 167-184. Leiden: Sidestone Press.

Meskell, L. 2013. A thouroughly modern park: Mapungubwe, UNESCO and Indigenous Heritage. In A. GonzбlezRuibal, Reclaiming Archaeology: Beyond the Tropes of Modernity, pp. 244-257. Oxon: Routledge.

Mol, A. 2014. Play-Things and the Origins of Online Networks: Virtual material culture in multiplayer games. Archaeological Review from Cambridge, 29(1), pp. 144-166.

Morgan, C. 2017. An Unexpected Archaeology: An Interventionist Strategy for Video Games and Archaeology. The SAAArchaeological Record, March, 28-33.

Morgan, C. 2019. Avatars, Monsters, and Machines: A Cyborg Archaeology. European Journal of Archaeology, March, 1-14.

Morton, T. 2013. Hyperobjects: Philosophy and Ecology after the End of the World. Minneapolis: University of Minnesota Press.

Mueller, K., \& Riegler, A. 2014. Second-Order Science: A Vast and Largely Unexplored Science Frontier. Constructivist Foundations, 10(1), 7-15.

Muriel, D., \& Crawford, G. 2018. Video Games As Culture: Considering the Role and Importance of Video Games in Contemporary Society. Oxon: Routledge.

Olsen, B., Shanks, M., Webmoor, T., \& Witmore, C. 2012. Archaeology: The Discipline of Things. California: University of California Press.

Orser, C. E. 2013. The politics of periodization. In A. Gonzбles-Ruibal, G. Lucas, \& C. Witmore, eds. Reclaiming Archaeology: Beyond the Tropes of Modernity, pp. 145-154. Oxon: Routledge.

Orser, C. E. 2015. Archaeological Thinking: How to Make Sense of the Past. Lanham: Rowman \& Littlefield. 
PC Gamer. 2019. Assassin's Creed Unity needed to increase server capacity years after launch following the giveaway. [online] [acessed July 2019]. Available at: $<$ https://www.pcgamer.com/assassins-creed-unity-needed-to-increaseserver-capacity-years-after-launch-following-giveaway $>$

Perry, S., \& Morgan, C. 2015. Materializing Media Archaeologies: The MAD-P Hard Drive Excavation. Journal of Contemporary Archaeology, 2(1), pp. 94-104.

Plothe, T. 2016. The Princess Doesn't Leave the Castle: How Nintendo's WiiWare Imprisons Indie Game Design. In S. Conway, \& J. de Winter, eds. Video Game Policy: Production, Distribution, and Consumption, pp. 42-53. Oxon: Routledge.

Porsdam, H. ed. 2015. Copyrighting Creativity: Creative Values, Cultural Heritage Institutions and Systems of Intellectual Property. Surrey: Ashgate.

Price, S. 1995. Conservations on Archaeological Excavations (2nd ed.). Rome: ICCROM.

Reinhard, A. 2018. Archaeogaming: An Introduction to Archaeology in and of Video Games. New York: Berghahn Books.

Renfrew, C., \& Bahn, P. 2004. Archaeology: The Key Concepts. Oxon: Routledge.

Renfrew, C., \& Bahn, P. 2016. Archaeology: Theories, Methods and Practice (7th ed.). London: Thames \& Hudson.

Reynolds, R. 2016. Play Britannia: The Development of U.K. Video Game Policy. In S. Conwayy, \& J. de Winter, eds. Video Game Policy: Production, Distribution, and Consumption. Oxon: Routledge, pp. 113-127. Oxon: Routledge.

Ruffino, P. 2018. Future Gaming: Creative Interventions in Video Game Culture. London: Goldsmiths Press.

Shanks, M. 1998. The Life of an Artifact in an Interpretive Archaeology. Fennoscandia archaeologica , XV, 15-30.

Stobiecka, M. 2018. Digital Escapism: How Do Objects Become Deprived of Matter. Journal of Contemporary Archaeology, 5(2), 194-212.

The Guardian. 2019. Assassin's Creed creators pledge $\square 500,000$ to Notre Dame. [online] [accessed July 2019] Available at: <https://www.theguardian.com/games/2019/apr/17/assassins-creed-creators-pledge-500000-notredame-restoration>

Tilden, F. 1977. Interpreting Heritage (3rd ed.). Chapel Hill: University of North Carolina Press.

Trigger, B. G. 2006. A History of Archaeological Thought (2nd ed.). Cambridge: Cambridge University Press.

Twenge, J. M. 2017. iGen: Why Today's Super-Connected Kids Are Growing Up Less Rebellious, More Tolerant, Less Happy and Completely Unprepared for Adulthood and What That Means for the Rest of Us. New York: Atria Books.

Vie, S. 2016. Policies, Terms of Service, and Social Networking Games. In S. Conway, \& J. de Winter, eds. Video Game Policy: Production, Distribution, and Consumption, pp. 54-67. Oxon: Routledge.

von Foerster, H. 2003. Understanding Understanding: Essays on Cybernetics and Cognition. New York: Springer Verlag.

von Foerster, H., \& Purksen, B. 2001. Wahrheit ist die Erfindung eines Lıgners: Gesprдche fbr Skeptiker (4th ed.). Heidelberg: Carl-Auer-Systeme Verlag.

Wild, W. 1985. Tradition und Fortschritt. In ICOM, \& H. Auer, ed. Chance und Grenzen moderner Technologien im Museum, pp. 18-32. Mbnchen: Sauer Verlag. 